\title{
Body Mass Index and Health Related Quality of Life Using EQ-5D-5L: A Study among Reproductive Age Group Women of Urban Bhubaneswar
}

\author{
Adrija Roy, Ipsa Mohapatra, and O. P. Panigrahi
}

\begin{abstract}
Background: The National Family Health Survey (NFHS-4) reported that in India there are $22.9 \%$ underweight and $20.6 \%$ overweight and obese women. Considering only urban areas, the proportions are $15.5 \%$ and $31.3 \%$ respectively. Not only does having an abnormal BMI affect the health, but also has a negative impact on their overall wellbeing. In this study, we aimed to find out the BMI and Health-related quality of life and the association between them.

Methods: A community-based cross-sectional study was conducted among 210 reproductive age-group women residing in urban Bhubaneswar using a predesigned, pretested, semistructured questionnaire. Data on socio-demographic characteristics, marital status, height, weight, BMI, Waist-Hip ratio (WHR) and Health related quality of life (HRQOL) was collected. Chi-square \& F-test, wherever appropriate were applied to find out the associations and a p-value of $<0.05$ was considered significant.

Results: $62.9 \%$ of respondents were within normal-BMI range, $12.4 \%$ obese, $9.5 \%$ overweight,9\% underweight and $6.2 \%$ in pre-obese BMI category.WHR was found to be greater than 0.80 signifying moderate to high health risk in $63.3 \%$ women.64.8\% women indicated "no problems" and $35.2 \%$ indicated "problems" in their HRQOL. A statistically significant association $(p<0.05)$ was found between HRQOL and age group, literacy, age at marriage, parity and BMI. A highly significant statistical $(P<0.0001)$ association was reported between HRQOL and WHR. The women reported most problems in the Anxiety and depression dimension of the HRQOL.

Conclusions: There was a high prevalence of abnormal BMI among women. The reported HRQOL also indicated problems in its domains. A statistically significant association between BMI, WHR and HRQOL could be established. Targeted promotive and preventive strategies by IEC activities on lifestyle modification and proper nutrition are necessary to bring about a positive change in health and wellness.
\end{abstract}

Index Terms - Body Mass Index, Health Related Quality of Life, Reproductive age group women, Obesity.

\section{INTRODUCTION}

The National Family Health Survey (NFHS-4) reported that in India there are $22.9 \%$ underweight women and $20.6 \%$ overweight and obese women. When considering only urban areas, the proportions are $15.5 \%$ and $31.3 \%$ respectively [1]. Not only does having an abnormal BMI affect the overall health and nutrition, but also the overall wellbeing of individuals is negatively affected.

Published on July 18, 2020.

A. Roy, All India Institute of Medical Sciences, India.

(e-mail: dradrijaroy ${ }^{\circledR}$ gmail.com)

I. Mohapatra, Kalinga Institute of Medical Sciences, India.

(corresponding e-mail: dr_ipsa@yahoo.co.in)
The Body mass index (BMI) is used for defining a height/weight characteristics in adults and for classifying (categorizing) them into groups. The common interpretation is that it represents an index of an individual's fatness. It also is widely used as a risk factor for the development of or the prevalence of several health issues. The BMI has been useful in population-based studies by virtue of its wide acceptance in defining specific categories of body mass as a health issue [2]. It is also used for the determination of nutritional status or body composition. It is the value obtained when the weight in kilograms is divided by the square of the height in meters [2].

The WHO criteria for BMI classification was widely used for the assessment of nutritional status. However, in recent years some scientists in the Asia- Pacific region made recommendations that the criteria values be modified to fit the Asian body composition, which is claimed to be different compared to the American or European body composition. Thus the "Asian criteria" for the determination of nutritional status based on the BMI was conceived off in the year 2003 [3]. It was later adopted by several Asian countries including India. Asian Indians tend to have more visceral adipose tissue, despite having lean BMI [4]. Therefore, they are prone to more to insulin resistance, cardiovascular risk and morbidities of various other systems. Values are ageindependent \& same for both sexes. At similar BMI, fat content in women is more than men. Obesity is one of the major causes of an array of non-communicable diseases. However, morbidity and mortality are not the only two consequences of obesity; health-related quality of life (HRQOL), which focuses on the impact of health status on quality of life, including domains related to physical, mental, emotional and social functioning, is also impacted by obesity [5].

The measurement of health and the effects of health care must include not only an indication of changes in the frequency and severity of diseases but also an estimation of well-being and this can be assessed by measuring the improvement in the Health related quality of life (HRQOL)related to health care [6].

WHO defines Health related quality of life (HRQOL) as individuals' perception of their position in life in the context of the culture and value systems in which they live and in relation to their goals, expectations, standards and concerns. It is a broad-ranging concept affected in a complex way by

O. P Panigrahi Kalinga Institute of Medical Sciences, India (e-mail: ompanigrahi@ ${ }^{@}$ gmail.com). 
the person's physical health, psychological state, level of independence, social relationships, personal beliefs and their relationship to salient features of their environment [6].

The HRQOL of various strata of apparently healthy and unhealthy individuals have been assessed worldwide, but there is a noticeable lack of research and paucity of data among reproductive age group women (15-49 years.), especially in developing countries. This study, therefore, assesses these two important aspects of BMI and HRQOL among the reproductive age group women in urban Bhubaneswar, Odisha.

\section{Objectives:}

1. To find out the BMI status of reproductive age group women of urban Bhubaneswar.

2. To assess their Health-Related Quality of Life.

3. To find out any association between their BMI status and Health Related Quality of life.

\section{MAterials And Methods}

Study type: It was a community-based cross-sectional study.

Field of study: Urban areas (both slum and non slum) of Bhubaneswar, Odisha.

Study Population: Women of reproductive age group (15$49 \mathrm{yrs}$ ) residing in urban areas of Bhubaneswar consisted of the study population.

Study duration: 2 years (October 2015 to October 2017.)

Inclusion criteria:

1. Women in the reproductive age group (15-49yrs)

2. All such women who gave informed written consent to participate in the study.

3. Women permanently residing in Bhubaneswar (since at least 1year).

\section{Exclusion criteria:}

1. Pregnant and lactating women.

2. Women who had attained menopause (natural and surgical).

3. Mentally ill women and women with a chronic debilitating illness.

4. Migration in between study period.

Sample Size: Sample size was calculated, taking, prevalence (p) as 50\%, confidence interval of 95\%, allowable error (d) as $10 \%$ and design effect (DEEF) as 2 the sample size was calculated to be 200 . Adding a non-response rate of $5 \%$, a final sample size of 210 was considered for the study.

\section{Sampling Technique:}

A two-stage cluster random technique was used to identify the study participants. The city of Bhubaneswar is divided into 3 geographical zones (north, south-west, south-east) a simple random sampling was used to identify 2 (north, southwest) of the 3 zones. Each zone had wards, so in this stage, simple random sampling was used again to identify the clusters (wards). To identify the first household a central location was identified and by spinning a bottle and fixing a direction and thereafter to identify first household simple random sampling was used. A total of 21 wards (clusters) were identified for the study (11 wards from North Zone as the population was higher, and 10 from South-east zone) and then 10 households were selected from each ward. Kish Grid Technique [7]. was used for the selection of study participants within each identified household.
Outcome Variable: Primary outcome variable of the study was the HRQOL of the reproductive age group women. The association of BMI with HRQOL was therefore necessarily noted.

Explanatory variable: BMI was the major explanatory variable. Variables like WHR, sociodemographic characteristics also were calculated and thus their association with HRQOL was measured.

\section{Study tool and data collection:}

A predesigned, pretested, semi-structured interview schedule was used to collect data. It was divided into 3 parts.

$>\quad$ Part A consisted of questions on the sociodemographic characteristics, menstrual and obstetric history of the women. Modified Kuppuswami Scale [8] was used to analyse the socio-economic status.

> Part B consisted of anthropometric measurements including height, weight, BMI, waist and hip circumference. BMI was categorized according to Asian Criteria (Underweight <18.5, Normal range 18.5-22.9, Overweight 23-24.9, Pre-obese 25-29.9, Obese $\geq 30$ ). The WHR was also depicted according to Asian cut off values (WHR $<0.80$ signifying low health risk and WHR >0.80 signifying moderate to high health risk) [9].

$>\quad$ Part $\mathrm{C}$ of the schedule included the standardized Euro Quality of life -5 Dimension -5 Level (EuroQol-5D-5L or EQ-5D-5L) [10] internationally validated questionnaire to measure the Health Related Quality of Life . The time recall used was during the past 1 month. The descriptive system comprises five dimensions: mobility, self-care, usual activities, pain/discomfort and anxiety/depression. Each dimension has five levels: no problems, slight problems, moderate problems, severe problems and extreme problems. For the purpose of analysis of HRQOL, in each dimension, level 0 was taken as "no problem" and "good health related quality of life" , and level 1,2,3,4,5 as indicating "problems" as "not good health related quality of life". The EQ visual analogue scale (EQ-VAS) reports a participant's self-rated health on a $20 \mathrm{~cm}$ vertical scale. This scale is numbered from 0 (worst possible health) to 100 (best possible health). [10], [11].

The interview schedule was translated into the local language (Odia) with the help of a certified translator and then back-translated to English to ensure quality. This was done for a better understanding of the study subjects.

\section{ETHICAL COMMITTEE APPROVAL}

Ethical Clearance was obtained from the Institutional Ethics Committee of Kalinga Institute of Medical Sciences, Bhubaneswar (Ref No.- KIMS/KIIT/IEC/117/2015).

\section{Data Management And Statistical Analysis}

Data was entered in MS Excel and analysed in SPSS version 20. Chi-square and Fishers Exact-tests were applied to find out the associations and a p-value of $<0.05$ was considered statistically significant. 


\section{RESUlts}

A total of 210 reproductive age group women (15-49 years) were surveyed, of which majority $(52.4 \%)$ were in the age group of $\leq 30$ years, $30 \%$ in $31-40$ years age group and $17.6 \%$ were $\geq 40$ years of age. The mean \pm S.D. age of the study participants was found to be $30.49 \pm 8.45$ years with a range of 16-45 years. A majority (72.9\%) of the women were homemakers.

Among the study subjects, the majority (62.9\%) were within a normal BMI range. As many as $12.4 \%$ of the study participants were obese, $9.5 \%$ were overweight, and $9 \%$ were underweight, rest of the women $(6.2 \%)$ belonged to pre-obese BMI category (Fig. 1). The waist: hip ratio (WHR) was found to be greater than 0.80 signifying moderate to high health risk in $63.3 \%$ women.

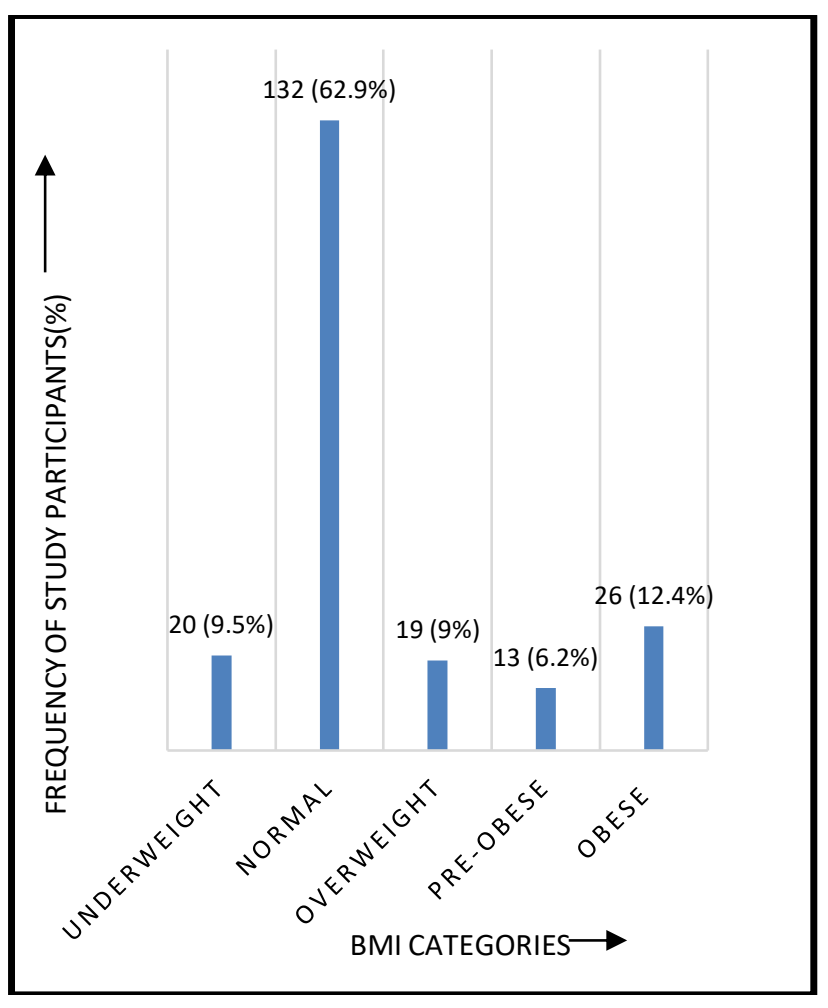

Fig. 1. Distribution of study participants according to Body Mass Index (BMI) categories $(\mathrm{N}=210)$.

The HRQOL was assessed using the EQ-5D-5L ${ }^{9}$ where level 1 indicates "no problems" and level 2, 3, 4, 5 have been clubbed together to indicate "problems". In our study, it was found that $136(64.8 \%)$ women indicated "no problems" and $74(35.2 \%)$ women indicated "problems" in their healthrelated quality of life.

The distribution of study participants according to sociodemographic characteristics, BMI, along with HRQOL has been shown in Table 1. A statistically significant association $(\mathrm{p}<0.05)$ was found between HRQOL and age group, literacy, age at marriage, parity and BMI. A highly significant statistical $(p<0.0001)$ association was found between HRQOL and WHR. No significant association could be established between HRQOL and religion, caste, socioeconomic status, occupation, income and marital status.

Table 2 indicates the distribution of the study participants according to the various dimensions of HRQOL according to EQ-5D-5L where among the study subjects who indicated problems in the dimension of mobility $40.9 \%$ were obese. Problems in the self-care dimension were majorly reported by study subjects with normal BMI status. $40.7 \%$ of women reporting problems in usual activity dimension belonged to normal BMI category and $37 \%$ were obese. Problems in the anxiety/depression dimension were also reported by $20.5 \%$ obese study subjects.

TABle 1: SOCIO-DEMOGRAPHIC PROFILE OF THE STUDY SUBJECTS AND ITS ASSOCIATION WITH HEALTH RELATED QUALITY OF LIFE (HRQOL) $(\mathrm{N}=210)$

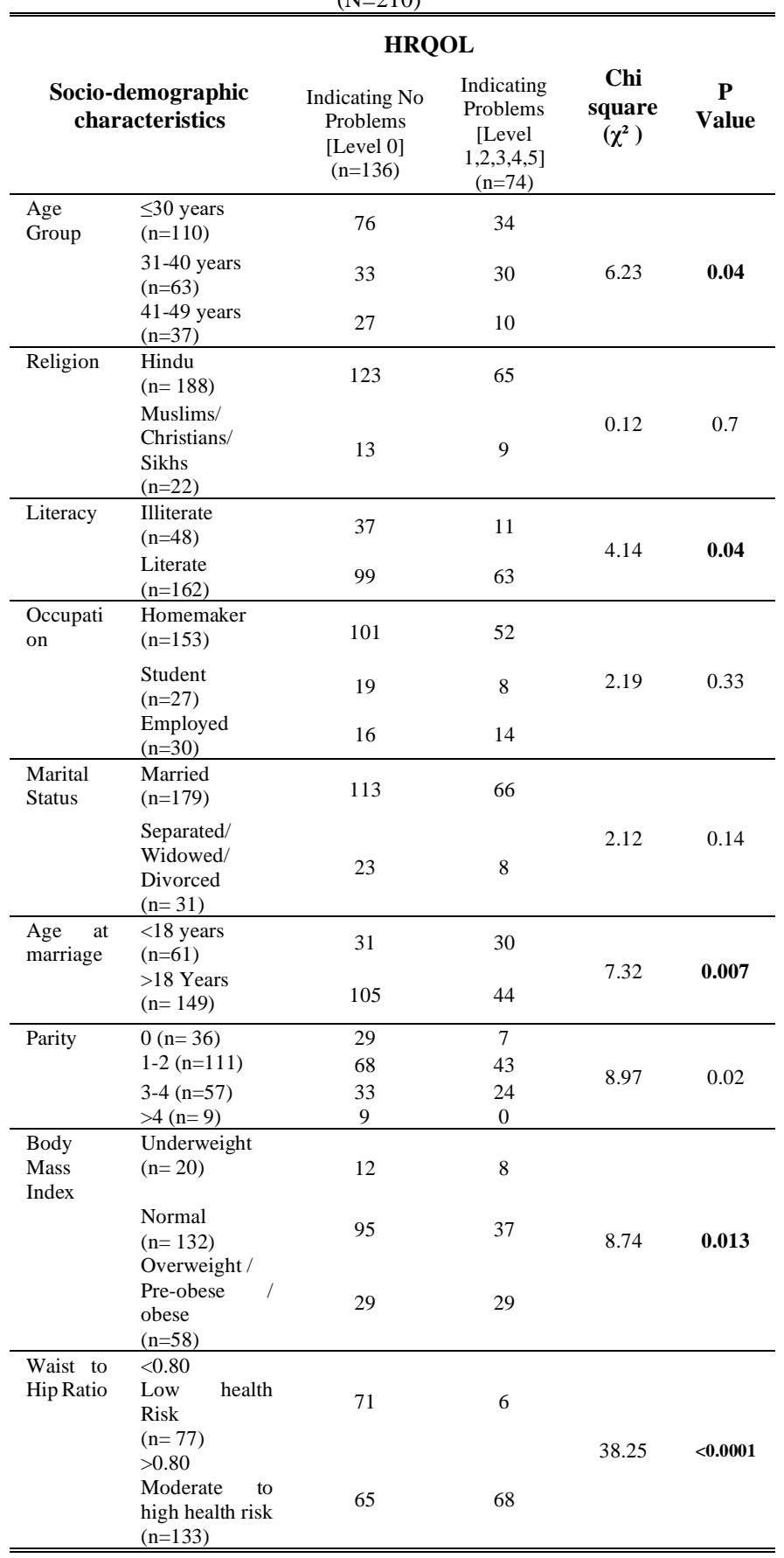


TABLE 2: BMI CATEGORY-WISE DISTRIBUTION OF STUDY PARTICIPANTS WITH PROBLEMS IN DIMENSIONS OF HRQOL

\begin{tabular}{cccccc}
\hline \hline $\begin{array}{c}\text { Dimensions of } \\
\text { HRQOL }\end{array}$ & $\begin{array}{c}\text { Under- } \\
\text { weight }\end{array}$ & Normal & $\begin{array}{c}\text { BMI categories } \\
\text { Over- } \\
\text { weight }\end{array}$ & Pre-obese & Obese \\
\hline \hline $\begin{array}{c}\text { Mobility } \\
(\mathbf{n}=\mathbf{2 2})\end{array}$ & $\begin{array}{c}4 \\
(18.2 \%)\end{array}$ & $\begin{array}{c}0 \\
(0 \%)\end{array}$ & $\begin{array}{c}4 \\
(18.2 \%)\end{array}$ & $\begin{array}{c}5 \\
(22.7 \%)\end{array}$ & $\begin{array}{c}9 \\
(40.9 \%)\end{array}$ \\
\hline $\begin{array}{c}\text { Self-care } \\
(\mathbf{n}=\mathbf{2 4})\end{array}$ & $\begin{array}{c}4 \\
(16.7 \%)\end{array}$ & $\begin{array}{c}15 \\
(62.5 \%)\end{array}$ & $\begin{array}{c}5 \\
(20.8 \%)\end{array}$ & $\begin{array}{c}0 \\
(0 \%)\end{array}$ & $\begin{array}{c}0 \\
(0 \%)\end{array}$ \\
\hline $\begin{array}{c}\text { Usual activity } \\
(\mathbf{n}=\mathbf{2 7})\end{array}$ & 0 & $\begin{array}{c}11 \\
(0 \%)\end{array}$ & $\begin{array}{c}5 \\
(40.7 \%)\end{array}$ & $\begin{array}{c}1 \\
(18.5 \%)\end{array}$ & $\begin{array}{c}10.7 \%) \\
(37.1 \%)\end{array}$ \\
\hline $\begin{array}{c}\text { Pain and } \\
\text { discomfort } \\
(\mathbf{n}=\mathbf{3 1})\end{array}$ & $\begin{array}{c}5 \\
(16.1 \%)\end{array}$ & $\begin{array}{c}12 \\
(38.7 \%)\end{array}$ & $\begin{array}{c}4 \\
(12.9 \%)\end{array}$ & $\begin{array}{c}5 \\
(16.1 \%)\end{array}$ & $\begin{array}{c}5 \\
(16.1 \%)\end{array}$ \\
\hline $\begin{array}{c}\text { Anxiety and } \\
\text { depression } \\
(\mathbf{n = 4 4 )}\end{array}$ & $\begin{array}{c}2 \\
(4.5 \%)\end{array}$ & $\begin{array}{c}20 \\
(45.5 \%)\end{array}$ & $\begin{array}{c}(18.2 \%) \\
(11.4 \%)\end{array}$ & $\begin{array}{c}9 \\
(20.5 \%)\end{array}$ \\
\hline \hline
\end{tabular}

(* Multiple responses).

A Visual acuity scale (VAS) was used to assess the health score of the current day and most (81\%) of the study participants scored as more than fifty. Only $19 \%$ of the study participants gave themselves a health score of less than or equal to 50 . The mean \pm S.D. health score of the study participants was found to be $72.73 \pm 22.02$.

\section{Discussions}

In the study, among 210 reproductive age group women residing in the urban area of Bhubaneswar, Odisha, it was found that their mean age ( \pm S.D) of the study population was $30.49 \pm 8.45$ years, and belonged to the Hindu $(90 \%)$ religion. $12.4 \%$ of the study participants were obese, $9.5 \%$ were overweight, and $9 \%$ were underweight, rest of the women (6.2\%) belonged to pre-obese BMI category. A study done in Kerala, India by Prahlad $P$ et al. [12] reported that mean age of the study population was 33.47 yrs with Standard Deviation (SD) of $8.11 \mathrm{yrs}$, which was almost similar to the current study. The prevalence of obesity based on BMI WHO classification for adult Asians was $47.5 \%$ in their study. This difference could be attributed to the fact that the study setting was different, the latter being done in rural India. Another study done in the urban adult population in western India by Shukla HC et al. [13] reported that $30 \%$ of women were overweight (BMI $>25 \mathrm{~kg} / \mathrm{m} 2$ ). According to NFHS-4 in urban areas, the proportions of underweight and overweight/obesity were $15.5 \%$ and $31.3 \%$ respectively [1].

On assessing the HRQOL by using a validated EQ-5D-5L scale it was found that among the 210 reproductive age group women 136 (64.8\%) women indicated "no problems" and 74 $(35.2 \%)$ women indicated "problems" in their HRQOL. When assessing the association of HRQOL with different variables, a statistically significant association $(\mathrm{P}<0.05)$ was found between HRQOL and age group, literacy, age at marriage, parity and BMI. A highly significant statistical $(\mathrm{p}<0.0001)$ association between HRQOL and WHR was also found. No significant association could be established between HRQOL and religion, caste, socio-economic status, occupation, income and marital status. A Visual acuity scale (VAS) was used to assess the health score. (81\%) of the study, participants scored their health "more than 50" in the VAS. Only $19 \%$ of the study participants gave themselves a health score of less than or equal to 50 . The mean \pm S.D. health score of the study participants was found to be $72.73 \pm 22.02$. There are not many studies found that were done in Indian settings that assessed the association between HRQOL and BMI, but a study done in south-western Finland by authors Korhonen $P$ et al. [13] used both SF-36 and EQ-5D index reported that The EQ-5D index and Euro-QOL visual analogue scale scores decreased linearly with rising BMI in these women. Our study, therefore, reveals the importance of a healthy BMI in order to achieve a problem-free health related quality of life.

\section{Limitations}

Being a cross-sectional study, it was not possible to establish a causal association between health-related quality of life, Body mass Index and various other factors. In order to put forth a cause- effect relationship a longitudinal study would be required. Also, since there are a variety of scales measuring health related quality of life, it is important to explore other scales and conduct similar research

\section{Future scope of the study}

There is a scope for appropriate targeted Behaviour change communication (BCC) strategies which will help in specific lifestyle changes and in turn improve the health-related quality of life of the women.

\section{What is already known on this topic?}

Previous studies done in this area revealed that HRQOL is affected by abnormal BMI, but the urban reproductive age group women had not been specifically explored previously.

\section{What this study adds?}

There is a high prevalence of abnormal BMI among the reproductive age group women of urban Bhubaneswar. Not only so it has been found that there was a statistically significant association between body mass index, waist to hip ratio and health related quality of life.

\section{ACKNOWLEDGMENT}

We express our gratitude to the staff and health-workers of Urban Health and Training Centre, Kalinga Institute of Medical Sciences, Bhubaneswar; for their help in data collection and interview, of the study participants; to the interns who assisted during the data collection, and finally, the study participants.

\section{REFERENCES}

[1] International Institute for Population Sciences (IIPS) and ICF. 2017 National Family Health Survey (NFHS-4), 2015-16.

[2] Nuttall, F. Q. Body mass index: Obesity, BMI, and health: A critical review. Nutr. Today 50, 117-128 (2015).

[3] Lildo L.O , Mirasol R. , Comparison of Body Mass Index based nutritional status using WHO criteria versus "Asian" criteria: report from the Philippines. PhilSPEN Online Journal of Parenteral and Enteral Nutrition ,. 1-8 (2011).

[4] WHO. Waist Circumference and Waist-Hip Ratio: Report of a WHO Expert Consultation. World Heal. Organ. 8-11 (2008). doi:10.1038/ejen.2009.139.

[5] Wang, R. et al. Body mass index and health-related quality of life in adults: A population based study in five cities of China. Eur. J. Public Health 22, 497-502 (2012).

[6] Whoqol Group. Development of the World Health Organization WHOQOL-BREF quality of life assessment. Psychological medicine. 1998 May;28(3):551-8.

[7] Nemeth, R. Respondent selection within the household - A modification of the Kish grid 1 Introduction 2 Reasons for sampling households 3 The Kish grid. Meet. young Stat. 51 (2002). 
[8] Saleem SM. Modified Kuppuswamy socioeconomic scale updated for the year 2019. Indian Journal of Forensic and Community Medicine. 2019 Jan;6(1):1-3.

[9] Ahmad, N., Adam, S. I. M., Nawi, A. M., Hassan, M. R. \& Ghazi, H. F. Abdominal obesity indicators: Waist circumference or waist-to-hip ratio in Malaysian adults population. Int. J. Prev. Med. 2016, (2016).

[10] The EuroQol Group (1990). EuroQol-a new facility for the measurement of health-related quality of life. Health Policy 16(3):199208.

[11] Chattopadhyay, K., Chattopadhyay, C. \& Kaltenthaler, E. Healthrelated quality-of-life of coal-based sponge iron plant workers in Barjora, India: a cross-sectional study. BMJ Open 4, e006047 (2014).

[12] Prahlad P, Ramesh H. Obesity among Reproductive Age Women in Rural Kerala: A Hidden Threat. Nat'1 J Community Med 2017; 8(9):530-534.

[13] Shukla, H. C., Gupta, P. C., Mehta, H. C. \& Hebert, J. R. Descriptive epidemiology of body mass index of an urban adult population in Western India. J. Epidemiol. Community Health 56, 876-880 (2002).

[14] Korhonen, P. E., Seppälä, T., Järvenpää, S. \& Kautiainen, H. Body mass index and health-related quality of life in apparently healthy individuals. Qual. Life Res. 23, 67-74 (2014). 